\title{
Article \\ Design and Analysis of the 45kW-Class Magnetic Geared Permanent Magnet Synchronous Motor for Traction of Tram Vehicles
}

\author{
Jae-Hyeon Lim, Geochul Jeong (D), Hyung-Woo Lee, Jae-Bum Lee, Jong-Seok Lim and Chan-Bae Park*(D)
}

check for

updates

Citation: Lim, J.-H.; Jeong, G.; Lee, H.-W.; Lee, J.-B.; Lim, J.-S.; Park, C.-B.

Design and Analysis of the

45kW-Class Magnetic Geared

Permanent Magnet Synchronous Motor for Traction of Tram Vehicles. Appl. Sci. 2021, 11, 6360. https:// doi.org/10.3390/app11146360

Academic Editors: Gang Lei and Frede Blaabjerg

Received: 10 May 2021

Accepted: 6 July 2021

Published: 9 July 2021

Publisher's Note: MDPI stays neutral with regard to jurisdictional claims in published maps and institutional affiliations.

Copyright: (c) 2021 by the authors. Licensee MDPI, Basel, Switzerland. This article is an open access article distributed under the terms and conditions of the Creative Commons Attribution (CC BY) license (https:// creativecommons.org/licenses/by/ $4.0 /)$.
School of Railway Engieering, Korea National University of Transportation, 157 Cheoldobangmulgwan-ro, Uiwang-si 16106, Gyeonggi-do, Korea; dlawoguskr@naver.com (J.-H.L.); abcdjkc@naver.com (G.J.); krhwlee@ut.ac.kr (H.-W.L.); leejb@ut.ac.kr (J.-B.L.); imjong-seok@naver.com (J.-S.L.)

* Correspondence: cbpark@ut.ac.kr; Tel.: +82-31-460-0546

Abstract: The magnetic geared permanent magnet synchronous motor (MG-PMSM) is a PMSM that has two rotors with different rotation speeds and includes the function of magnetic gear. The design studies of the 45kW-class MG-PMSM are conducted for the application of the driving system for a tram. In this research, first, to derive the detailed model of the 45kW-class MG-PMSM for the tram, the analysis of the characteristics according to the stator winding method was performed. After selecting the winding method that can reduce the size of the MG-PMSM, two design topologies were applied to determine the number of stator poles, the number of outer rotor pole pieces, and the number of inner rotor poles of the MG-PMSM. A 45kW-class MG-PMSM detailed model was derived by applying a design topology that can minimize the size of the MG-PMSM, and it was confirmed that the required performance is satisfied through electromagnetic characteristics analysis. In addition, the $4.5 \mathrm{~kW}$-class small-scaled MG-PMSM prototype with concentrated winding was manufactured to verify the validity of the analytical model, and performance verification was performed.

Keywords: dual-rotor; MG-PMSM; dual airgap; pole piece; permanent magnet

\section{Introduction}

Recently, the weight reduction and floor-lowering of the vehicle-body have attracted much attention in the electric vehicle and railway vehicle market [1]. In addition, as researches for the weight reduction and floor-lowering of the railway vehicles are being actively conducted, the designs for miniaturization of driving devices for railway vehicles were considered prior to other electric equipment [2]. Figure 1 shows the urban railway vehicle and structure of bogies according to the type of railway vehicle. As shown in Figure 1, since the structure and the size of the railway vehicle bottom space are different for each railway vehicle, the structure and the size of the driving devices mounted on the bogie are different. As shown in Figure 1b, a bogie with a parallel-typed reduction gear is installed in general railway vehicles. In the case of a tram in Figure 1c, since the low-floor bogie was applied, there was not enough space to install a drive system inside the low-floor bogie, unlike the conventional railway vehicle bogie. The low-floor bogie for a tram has a complicated structure in which a mechanical reduction gear and a traction motor are vertically engaged with the outer side of the wheel. Therefore, in order to improve the efficiency and maintainability of the driving system for a tram, a structural simplification study of the conventional devices is required. In general, when changing a mechanical gear to a magnetic gear, the efficiency can be improved because there is no power transmission loss in the magnetic gear [3]. However, since it is difficult to achieve structural simplification only by applying magnetic gear, a magnetic-geared permanent magnet synchronous motor (MG-PMSM) is required. MG-PMSM, which has a double rotor that includes the function of a mechanical reduction gear, is a system that 
can completely replace the drive system consisting of a mechanical reduction gear and a traction motor. Figure 2 shows the structure of MG-PMSM and rotation principle by magnetic flux modulation in the double air gap of MG-PMSM. As shown in Figure 2, the MG-PMSM has two rotors that rotate at different speeds. In the case of the MG-PMSM, where the stator is located on the outside, the outer rotor is a low-speed-high-torque rotor (pole piece rotor), and the inner rotor is a high-speed-low-torque rotor (PM rotor). In general, the driving principle of MG-PMSM can be explained by the magnetic flux modulation principle of magnetic gear. As shown in Figure 2, it is possible to explain the principle of modulation of magnetic flux in two airgaps with the form of a linearly unfolded coaxial magnetic gear. In general magnetic gear, the space harmonic component of the magnetic field generated by the permanent magnet of the inner rotor in the inner air gap appears in the form of a space harmonic modulated in the outer air gap by the number of pole pairs of the inner permanent magnet and the number of pole pieces. Therefore, when a 3-phase power source with a frequency suitable for the modulated space harmonic component in the outer airgap is applied to the stator winding, the outer rotor and inner rotor of MG-PMSM rotate differently with a specific speed-torque ratio.

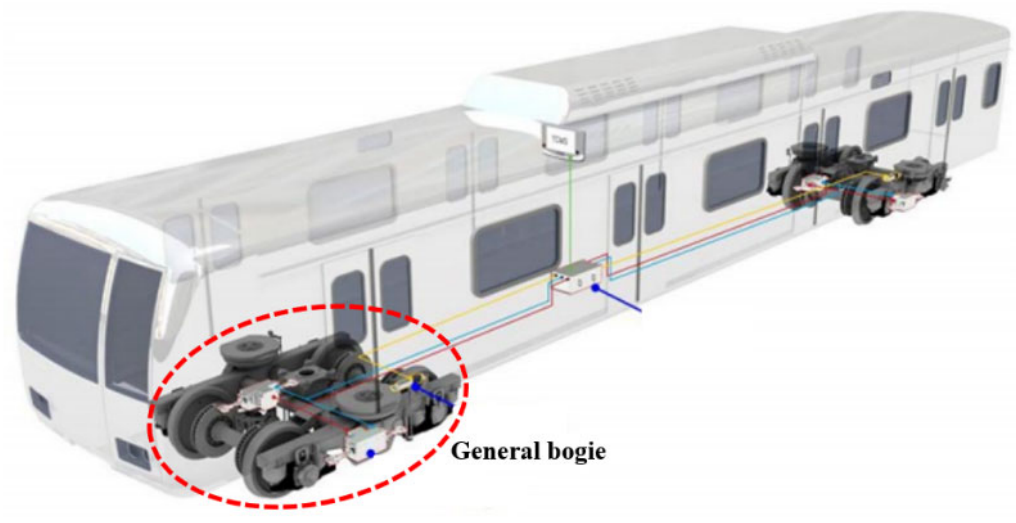

(a)

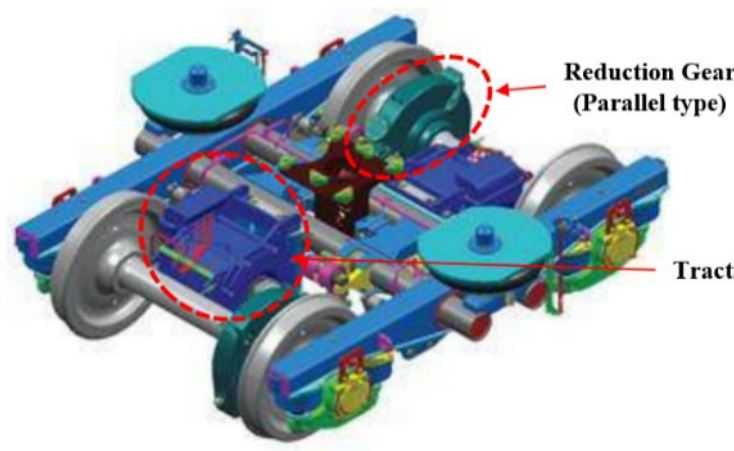

(b)

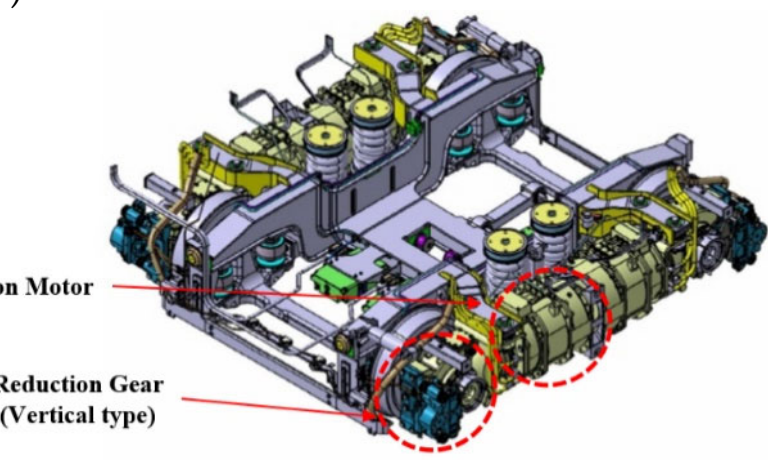

(c)

Figure 1. Urban railway vehicle and structure of the bogies according to the type of railway vehicle: (a) Urban railway vehicle (b) General bogie for railway vehicles; (c) Low-floor bogie for tram.

In this research, the design study of the 45kW-class MG-PMSM was conducted for the application of the MG-PMSM structurally integrated with magnetic gear and PMSM to the driving system for a tram. Figure 3 shows the structure of the bogie and conventional driving system for the low-floor tram. The conventional driving system for low-floor trams consists of a mechanical combination of a single-stage vertical-typed reduction gear and a traction motor. Figure 4 shows an application concept of MG-PMSM to a low-floor tram's driving system [4]. As shown in Figure 4, the outer rotor of MG-PMSM is directly connected to the wheel through a coupler. Since MG-PMSM must be installed in the bogie space where the conventional mechanical reduction gear system is installed, minimizing 
the size of the MG-PMSM is the main design goal in this study. In this research, first, to derive the detailed model of the 45kW-class MG-PMSM for the tram, the analysis of the characteristics according to the stator winding method was performed, and the studied stator winding method is the distributed winding and concentrated winding method. In general, the method of deriving the number of pole pieces in the design of MG-PMSM is divided into a method using the number of pole pairs of a permanent magnet rotor and a stator and a method using the number of stator slots instead of the number of stator pole pairs. The method using the permanent magnet and stator pole pairs is based on the general magnetic gear equation [5]. It was applied to the design of CVT application MG-PMSM by M. Cheng and C. Liu [6-10], outer rotor type MG-PMSM by J. Y. Choi and H. Shin [11,12], and decoupled type MG-PMSM by K. T. Chau [13]. On the other hand, a method using the number of pole pairs and stator slots of permanent magnets was presented in MG-PMSM by N. Niguchi [14-16]. A topology using the number of stator pole pairs was selected for the design of MG-PMSM in this research. After selecting the winding method that can reduce the size of the MG-PMSM, two design topologies were applied to determine the number of stator poles, the number of outer rotor pole pieces, and the number of inner rotor poles of the MG-PMSM. The detailed model was derived by applying the selected design topology that can minimize the size of the MG-PMSM, and it was confirmed that the required performances are satisfied through electromagnetic characteristics analysis. In order to accurately verify the validity of the $45 \mathrm{~kW}$ class MGPMSM design method for tram driving proposed in this research, a real model prototype should be applied. However, a 1/10 scaled model prototype was used in consideration of cost and test-bed conditions. A design model of a 4.5kW-class small-scaled MG-PMSM was derived by applying the design method suggested in this research, and the $4.5 \mathrm{~kW}$-class small-scaled MG-PMSM prototype was manufactured to verify the validity of the analytical model, and performance verification was performed. Through this research, it is expected that MG-PMSM, which has been reviewed only as a driving system for electric vehicles, will be reviewed as a driving system for railway vehicles. In addition, it is expected that the possibility of replacing the existing driving system for railway vehicles in terms of size and performance will be continuously reviewed.
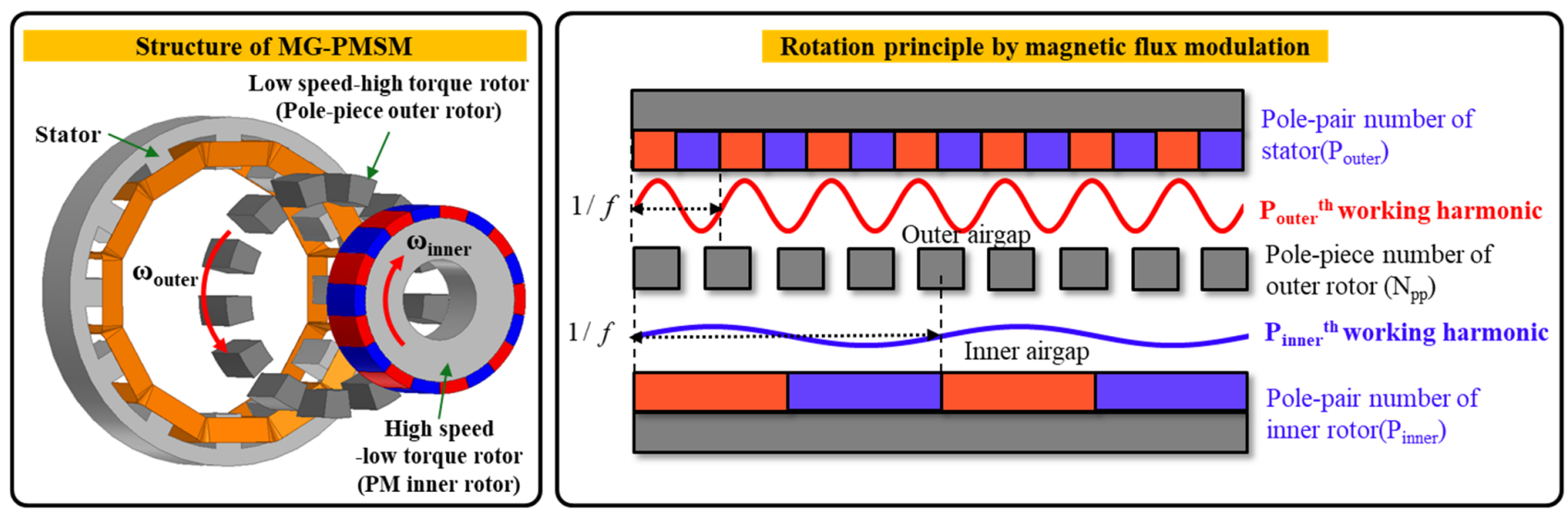

Figure 2. Structure of MG-PMSM and rotation principle by magnetic flux modulation in double air gap of MG-PMSM. 

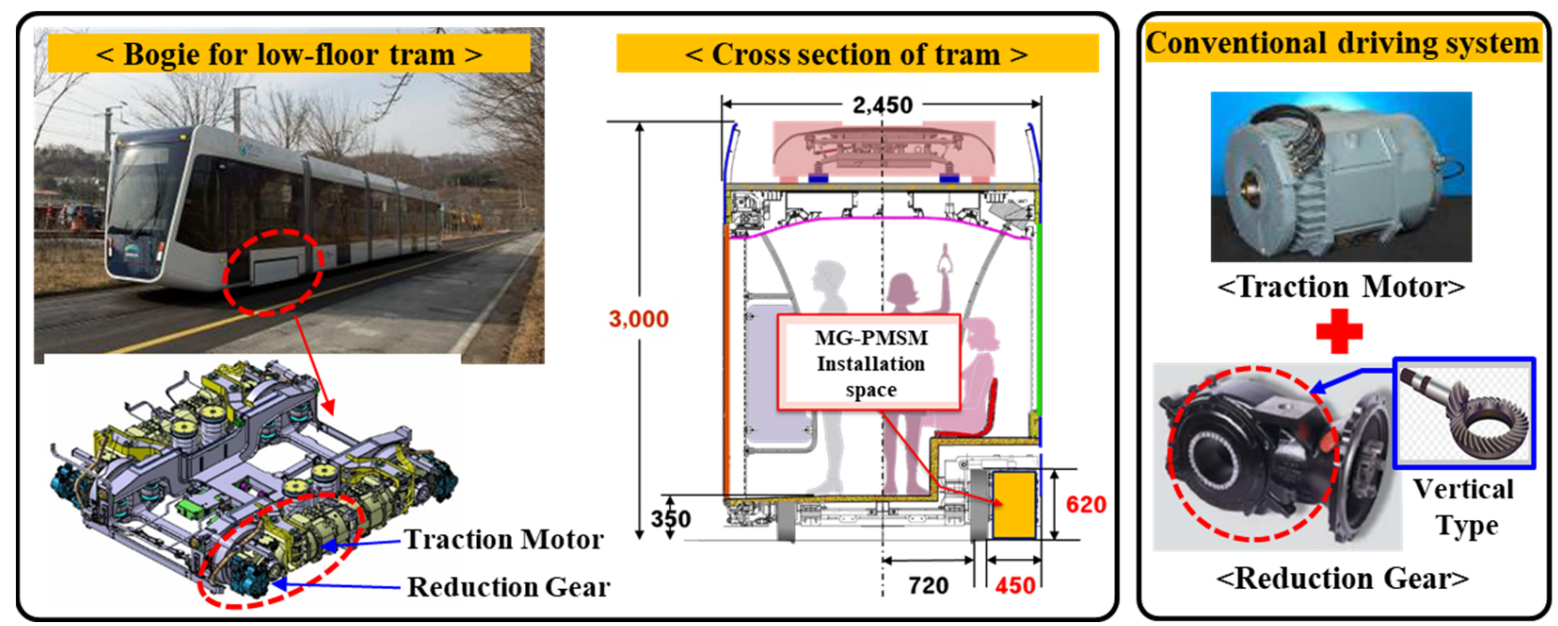

Figure 3. Structure of bogie and conventional driving system for the low-floor tram.

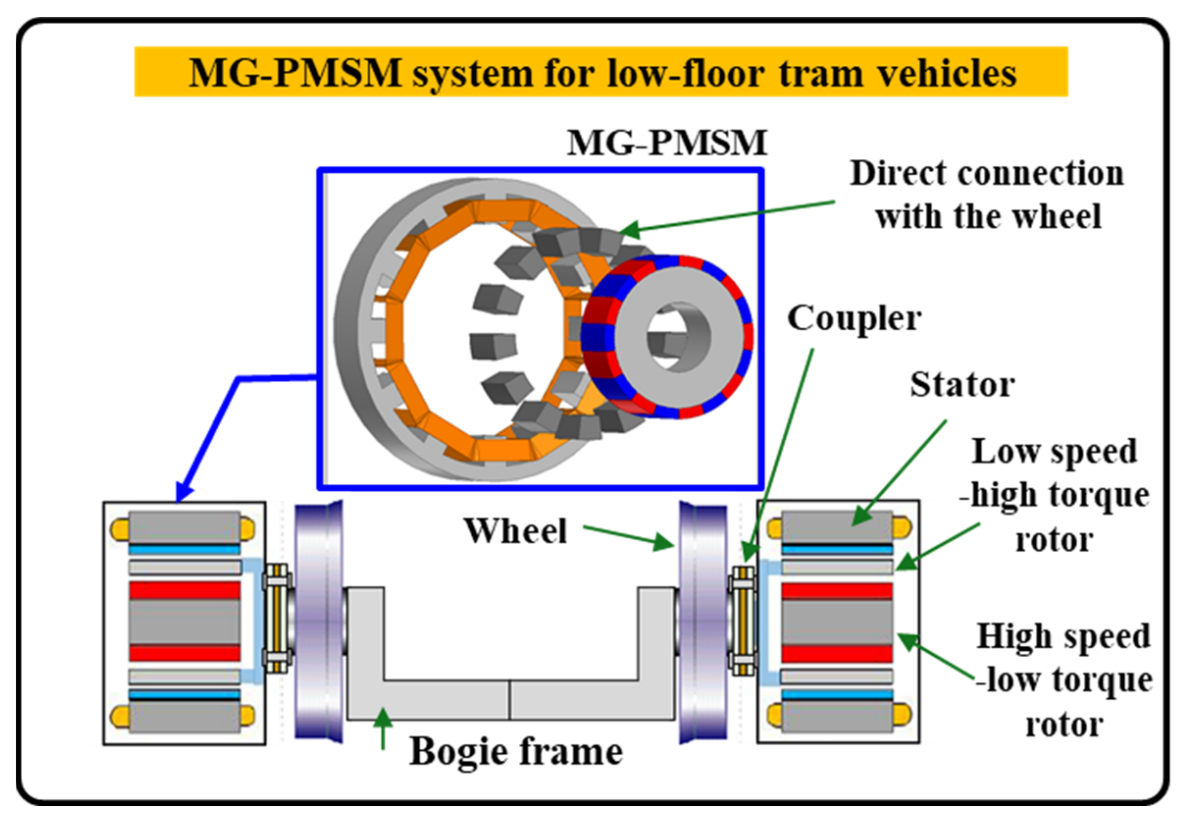

Figure 4. Application concept of MG-PMSM to low-floor tram driving system.

\section{Derivation of 45kW-Class MG-PMSM Basic Design Model}

\subsection{Structure of the Conventional Tram Vehicle and Design Target Specification of MG-PMSM}

As shown in Figure 3, a 3-phase induction motor and single-stage vertical-typed reduction gear with a gear ratio of 6.29 were adopted as a driving system of the conventional tram [17]. In this research, the 45kW-class MG-PMSM model smaller than the combined volume of the conventional traction motor and mechanical reduction gear should be derived. Table 1 shows the restrictions on the required design size of the $45 \mathrm{~kW}$ class MG-PMSM, and as shown in Figure 4, it was derived by considering the space available for installation through the space analysis of the existing tram bogie [18]. As shown in Table 1, The design restrictions of the MG-PMSM are a maximum of $520 \mathrm{~mm}$ based on the outer diameter of the stator core and $400 \mathrm{~mm}$ in the axial length direction. Figure 5 shows a required torque-speed curve of the low-speed part (wheel side) on the $45 \mathrm{~kW}$-class driving system for the Korean tram. As shown in Figure 5, the resulting model should generate $2000 \mathrm{Nm} / 717 \mathrm{Nm}$ of torque at rated and maximum speed (214 rpm/599 rpm). 
Table 1. MG-PMSM design criteria through installation space analysis.

\begin{tabular}{|c|c|}
\hline Contents & Design Criteria \\
\hline MG-PMSM installation space & Max. Dia. $620 \mathrm{~mm} /$ Depth $450 \mathrm{~mm}$ \\
\hline Required size of MG-PMSM & $\begin{array}{l}\text { Max. Dia. } 520 \mathrm{~mm} / \text { Depth } 400 \mathrm{~mm} \\
\text { (Based on the stator out dia.) }\end{array}$ \\
\hline Required torque & 2 kNm@214 rpm/0.71 Nm@599 rpm \\
\hline Efficiency & $92 \%$ \\
\hline
\end{tabular}

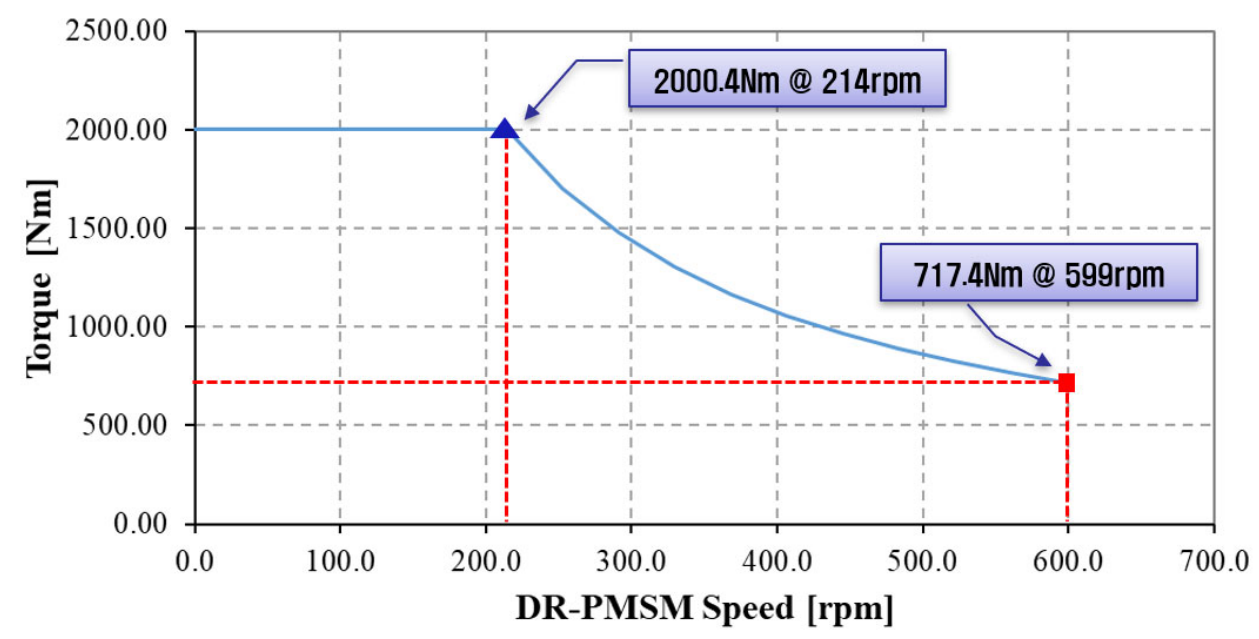

Figure 5. Required torque-speed curve of the low-speed part (Wheel side) on the 45kW-class driving system for the Korean tram.

\subsection{Derivation of MG-PMSM Design Model with Distributed Winding and Limits of Application for Tram Vehicle}

In this research, a new MG-PMSM design process is presented. This design technique is based on the existing PMSM design process as a method to design pole pieces in consideration of double airgap structure. Figure 6 shows the design process of the MGPMSM for tram vehicle traction as presented in this research. As shown in Figure 6, the basic model of the MG-PMSM can be derived using the magnetic load-electric load distribution method and the equivalent circuit method applied in the design of a general PMSM. In MG-PMSM, regardless of the MG-PMSM structure, the number of pole pieces in the outer rotor is derived from the combination of the respective pole pairs of the stators and the inner rotor magnet. In addition, it is derived from the combination of the rotational speed of the inner and outer rotors and the number of poles of pole pieces and permanent magnets [19].

In general, the stator winding method of a traction motor has a distributed winding and a concentrated winding, and the characteristics and size of the motor vary according to the winding method. A traction motor with a distributed winding has excellent control characteristics but has a disadvantage of increasing the volume due to the large end-turns $[20,21]$. Since the MG-PMSM must be installed in the bogie space where the conventional mechanical reduction gear system is installed, minimizing the size of the MG-PMSM is the main design goal in this study. In this research, first, to derive the detailed model of the $45 \mathrm{~kW}$-class MG-PMSM with distributed winding for the tram, the basic design model candidates according to the design parameter change in MG-PMSM are derived, and the torque and efficiency characteristics are compared. Table 2 shows a comparison of the design results of $45 \mathrm{~kW}$-class MG-PMSM basic design model candidates. As shown in Table 2, the design combination of Model 4 satisfies the rated torque and efficiency requirements. Therefore, the detailed design was carried out with a basic model with a 42 slots $/ 9$ pole pieces/14 magnet poles combination. Figure 7 shows the 
electromagnetic characteristics analysis results of the 45kW-class MG-PMSM design model with distributed winding derived through the detailed design process based on Model 4. Figure 7a shows the distribution of magnetic flux line and magnetic flux density (@Rated speed), and Figure 7b shows the electromagnetic characteristic analysis results (@Rated and max. speed). Table 3 shows the final design result of the 45kW-class MG-PMSM model with distributed winding, and as shown in Table 3, the final designed model satisfies the required electromagnetic performance but does not satisfy the size requirements. The reason is the influence of the large end-turn structure of the distributed winding method. Therefore, it is required to review the concentrated winding method in which the end-turn part is smaller than the distributed winding method.

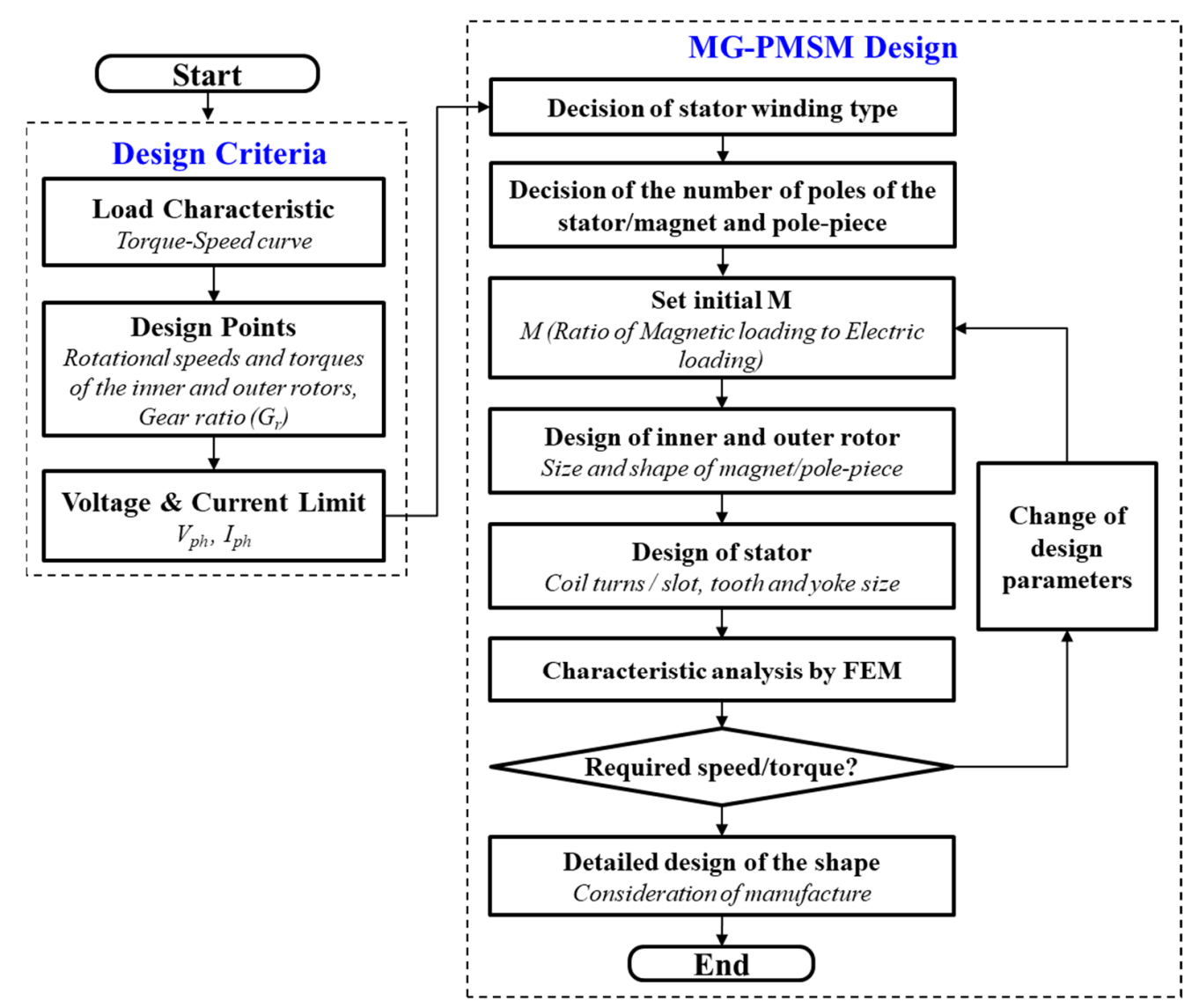

Figure 6. Design process of MG-PMSM for tram vehicle traction.

Table 2. Comparison of the design results of 45kW-class MG-PMSM basic design model candidates with distributed winding.

\begin{tabular}{ccccc}
\hline Contents & Model 1 (30 Slots) & Model 2 (30 Slots) & Model 3 (42 Slots) & Model 4 (42 Slots) \\
\hline Stator poles & 10 & 4 & 14 & 4 \\
\hline Pole pieces & 7 & 7 & 4 & 9 \\
\hline Rotor poles & 4 & 10 & 1.89 & 14 \\
\hline Rated torque $(\mathrm{kNm})$ & 2.04 & 2.16 & 17.5 & 7.4 \\
\hline Torque ripple $(\%)$ & 13.8 & 3.8 & 85.3 & 92.5 \\
\hline Efficiency $(\%)$ & 76.4 & 75.9 & & 95 \\
\hline
\end{tabular}




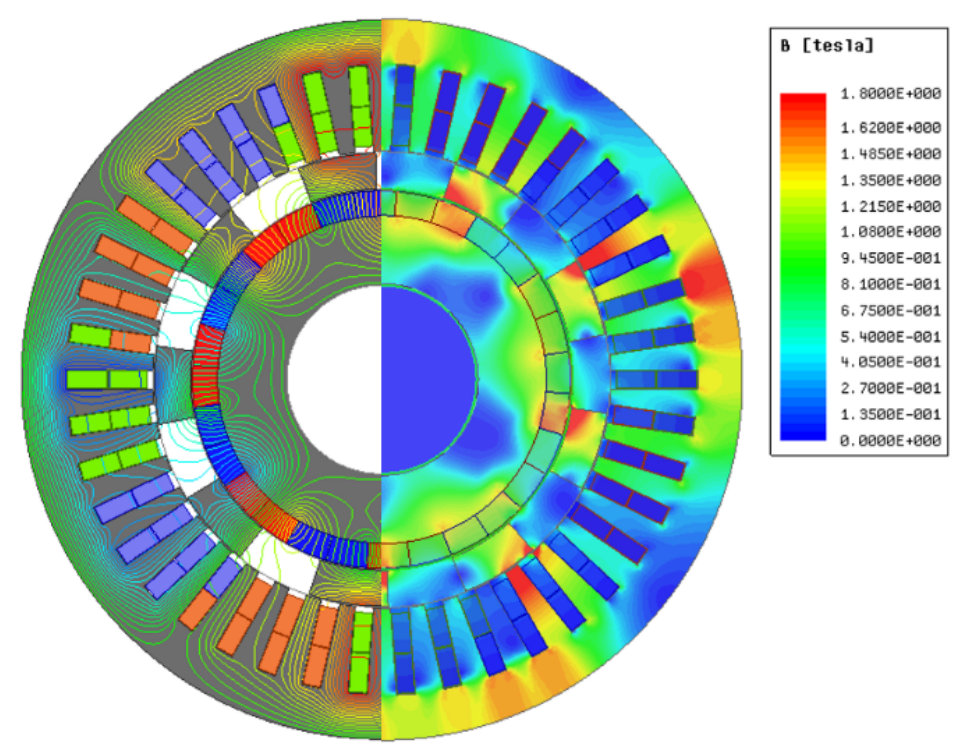

(a)
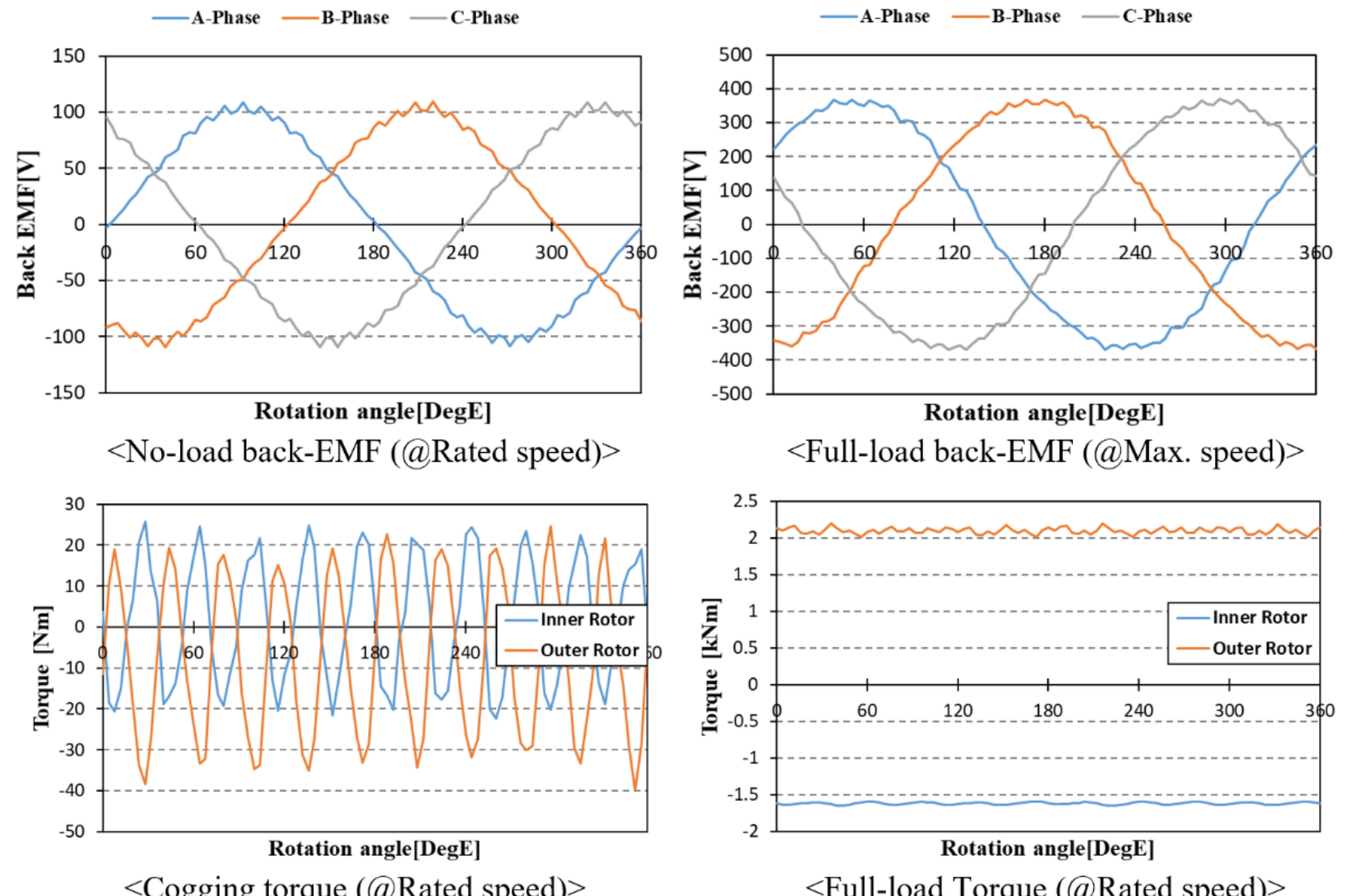

(b)

Figure 7. Electromagnetic characteristic analysis results of 45kW-class MG-PMSM design model with distributed winding derived through the detailed design process based on Model 4: (a) Distribution of magnetic flux line and magnetic flux density (@Rated speed); (b) Electromagnetic characteristic analysis results (@Rated and max. speed). 
Table 3. Specifications of 45kW-class MG-PMSM Design Model with Distributed winding.

\begin{tabular}{|c|c|}
\hline Contents & Value \\
\hline Stator slots/Stator poles/Pole pieces/Rotor poles & $42 / 4 / 9 / 14$ \\
\hline Gear ratio 1 (Pole pieces/Stator pole pairs) & 4.5 \\
\hline Gear ratio 2 (Rotor pole pairs/Stator pole pairs) & 3.5 \\
\hline Gear ratio 3 (Pole pieces/Rotor pole pairs) & 0.643 \\
\hline Outer Dia. Of stator/Stack length/Axial length with end turns & $508 / 267 / 480 \mathrm{~mm}$ \\
\hline DC link voltage/ $\mathrm{I}_{\text {Phase }} @$ Rated speed & $750 \mathrm{~V}_{\mathrm{dc}} / 115 \mathrm{~A}_{\mathrm{rms}}$ \\
\hline $\mathrm{T}_{\text {ave._rated }} /$ Torque ripple @ Rated speed & $2096.5 \mathrm{Nm} / 8.8 \%$ \\
\hline $\mathrm{T}_{\text {ave._max. } / \text { Torque ripple @ Max. speed }}$ & $758.1 \mathrm{Nm} / 15 \%$ \\
\hline THD (No-load/Full-load) @ Rated speed & $4.1 / 6.1 \%$ \\
\hline R Phase @ $20^{\circ} \mathrm{C} /$ Back-EMF $F_{\text {Phase-fund. }} @$ Max. speed & $0.094 \Omega / 249.6 \mathrm{~V}$ \\
\hline Copper loss/Iron loss/Eddy current loss in PM/Efficiency @ Rated speed & $1,243.3 / 133.2 / 64 \mathrm{~W} / 94.6 \%$ \\
\hline Core/Magnet material grade & 30PNF1600/NdFeB(38UH) \\
\hline
\end{tabular}

3. Detailed Design Study for 45kW-Class MG-PMSM with Concentrated Winding

3.1. Design Topology Study for MG-PMSM with Concentrated Winding

In general, there are two design topologies for determining the number of pole pieces of MG-PMSM. One is the method of applying the number of stator pole pairs and the number of permanent magnet rotor pole pairs, and the other is the number of stator slots and the permanent magnet rotor pole pairs. In this research, model A and model B are derived using two design topologies, respectively, to design the 45kW-class MG-PMSM with a concentrated winding.

Table 4 describes the two design topologies of the MG-PMSM with the concentrated winding applied in this research. As shown in Table 4, topology A uses the pole pairs of the stator, and topology B uses the slot numbers of the stator when deriving the number of pole pieces. Figure 8 shows the $45 \mathrm{~kW}$-class MG-PMSM design models with concentrated winding derived by applying two topologies, respectively. As shown in Figure 8, both models have 12 slots for the stator, but the number of stator poles, pole pieces, and permanent magnet rotor poles is different depending on the applied topology. Figure 9 shows a comparison of the electromagnetic characteristic waveforms of the designed models at rated speed (214 rpm). As shown in Figure 9, in the case of a full load back EMF and cogging torque characteristics, it can be confirmed that Model A is better than Model B. Table 5 shows a comparison of the results of various designs and characteristics of Model A and Model B designed in this study. As shown in Table 5, in terms of torque and efficiency, the characteristics of Model A are better than those of Model B, and in particular, in terms of size, it is possible to make Model A about $45 \%$ smaller than Model B. Therefore, in this research, the model designed by topology $\mathrm{A}$ is selected as the final model of the $45 \mathrm{~kW}$-class MG-PMSM with a concentrated winding. 
Table 4. Design Topologies of 45kW-class MG-PMSM Design Model with Concentrated winding.

\begin{tabular}{ccc}
\hline Contents & Model (Topology) A & Model (Topology) B \\
\hline Method of deriving the no. of pole piece & $N_{p p}=p_{f m}+p_{s}$ & $N_{p p}=2 p_{f m}+N_{s l o t s}$ \\
\hline Gear ratio & $G_{r 1}=\frac{p_{f m}+p_{s}}{p_{s}}=\frac{N_{p p}}{p_{s}} \quad G_{r 2}=\frac{p_{f m}}{p_{s}}$ & $G_{r}=\frac{N_{p p}}{p_{f m}}$ \\
\hline Speed-torque & $T_{p p}=T_{s} \cdot G_{r 1} T_{f m}=T_{s} \cdot G_{r 1}$ & $\omega_{f m}=G_{r} \cdot \omega_{p p}$ \\
\hline
\end{tabular}

$P_{s}$ : Stator pole pairs; $N_{p p}$ : No. of pole piece; $G_{r}$ : Pole piece-PM rotor pole pairs; $P_{f m}:$ PM rotor pole pairs; $N_{s l o t s}:$ No. of stator slots; $G_{r 1}$ : Pole piece-Stator pole pairs; $T_{s}, T_{p p}$ : Torque of stator and pole piece; $G_{r 2}$ : PM rotor pole pairs-Stator pole pairs' $\omega_{f m}:$ Speed of PM rotor [rad/s].
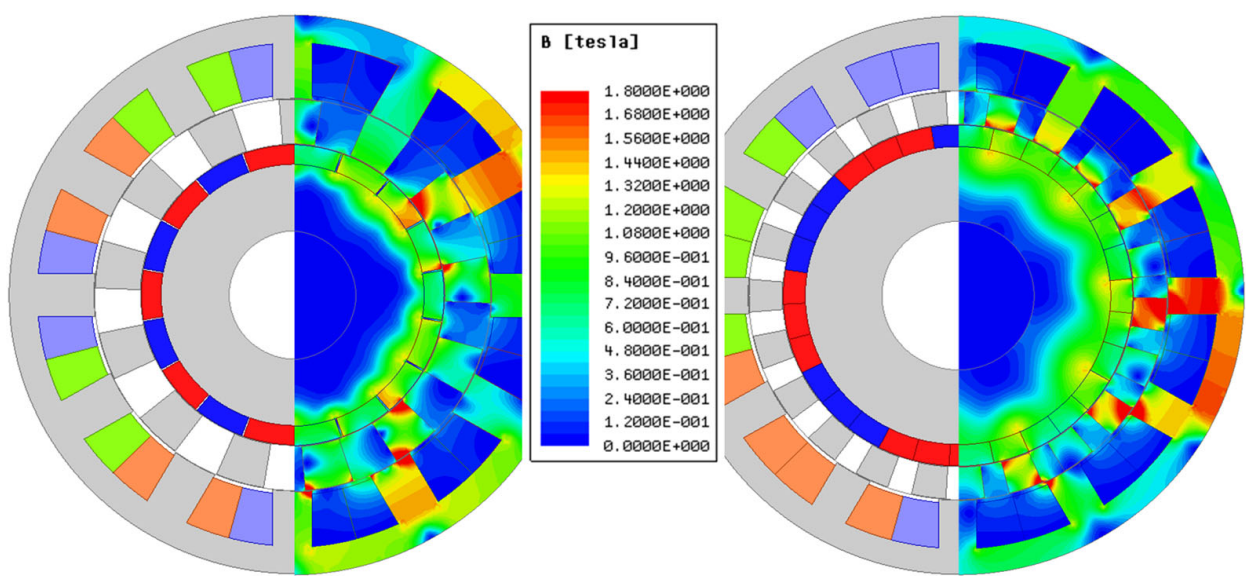

Figure 8. Design models and magnetic flux density distributions of 45kW-class MG-PMSM with concentrated winding ((Left): Model A, (Right): Model B).

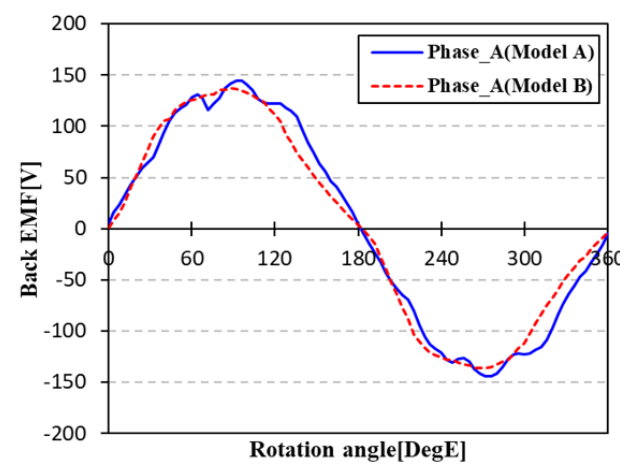

(a)

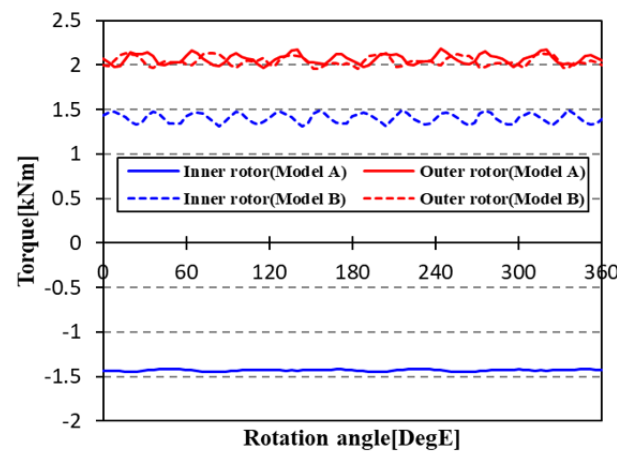

(c)

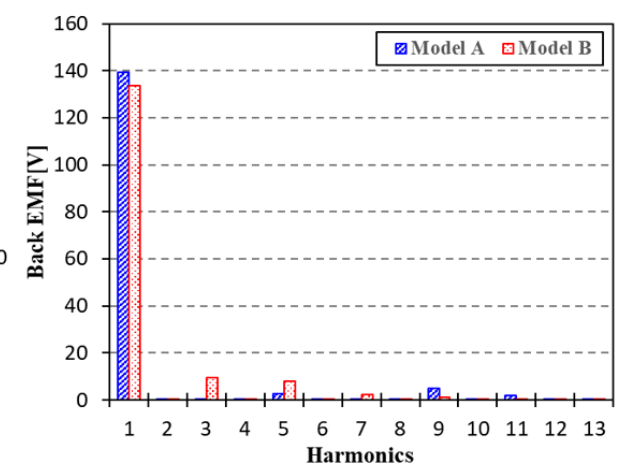

(b)

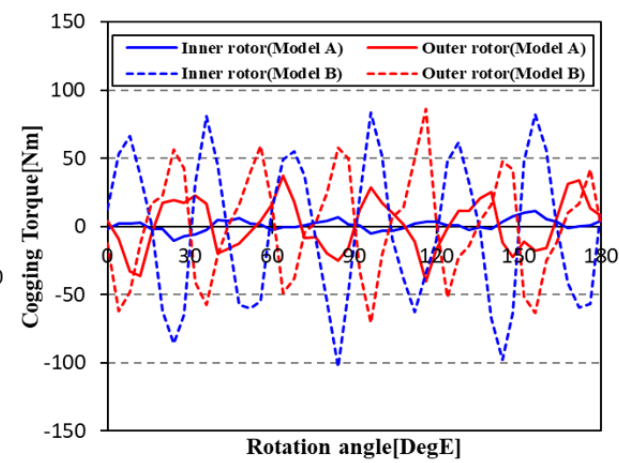

(d)

Figure 9. Electromagnetic characteristics of 45kW-class MG-PMSM design models with concentrated winding (@Rated speed): (a) Full-load back-EMF; (b) Full-load back-EMF harmonics; (c) Full-load torque; (d) Cogging torque. 
Table 5. Comparisons of 45kW-class MG-PMSM Design Models with Concentrated winding.

\begin{tabular}{|c|c|c|}
\hline \multirow{2}{*}{ Contents } & \multicolumn{2}{|c|}{ Value } \\
\hline & Model (Topology) A & Model (Topology) B \\
\hline Stator slots/Stator poles/Pole pieces/Rotor poles & $12 / 8 / 13 / 18$ & $12 / 10 / 22 / 10$ \\
\hline Gear ratio 1 (Pole pieces/Stator pole pairs) & 3.25 & 4.4 \\
\hline Gear ratio 2 (Rotor pole pairs/Stator pole pairs) & 2.25 & 1 \\
\hline Gear ratio 3 (Pole pieces/Rotor pole pairs) & 0.722 & 4.4 \\
\hline Outer Dia. Of stator/Stack length/Axial length with end turns & $\begin{array}{c}520 / 180 / 210 \mathrm{~mm} \\
(\text { Volume } 45 \% \mathbf{\nabla})\end{array}$ & $520 / 265 / 305 \mathrm{~mm}$ \\
\hline I Phase @ Rated speed & $258 \mathrm{~A}_{\mathrm{rms}}$ & $581 \mathrm{~A}_{\mathrm{rms}}$ \\
\hline $\mathrm{T}_{\text {ave._rated }} /$ Torque ripple @ Rated speed & $2068 \mathrm{Nm} / 10.7 \%$ & $2045 \mathrm{Nm} / 9.1 \%$ \\
\hline THD of Back-EMF (No-load/Full-load) @ Rated speed & $4.5 / 4.7 \%$ & $12.0 / 9.3 \%$ \\
\hline Back-EMF $F_{\text {Phase-fund. }} @$ Max. speed & $390 \mathrm{~V}$ & $374 \mathrm{~V}$ \\
\hline Copper loss/Iron loss/Eddy current loss in PM @ Rated speed & $1325 / 101 / 415 \mathrm{~W}$ & $1034 / 177 / 1359 \mathrm{~W}$ \\
\hline Efficiency@ Rated speed & $96.7 \%(2.98 \% \Delta)$ & $93.9 \%$ \\
\hline
\end{tabular}

\subsection{Derivation of the Detailed Design Model for 45kW-Class MG-PMSM with Concentrated Winding}

In this research, the detailed design of the 45kW-class MG-PMSM model with concentrated winding derived by topology A was conducted. Figure 10 shows the detailed design parameters selected to derive the final $45 \mathrm{~kW}$ MG-PMSM model and the results of the sensitivity analysis of parameters. As shown in Figure 10, the yoke width, PM thickness, and pole piece arc ratio are set as variable parameters, and it can be seen that the pole piece rotor torque and Back-EMF THD do not react sensitively according to the yoke width change. Figure 11 shows the final design model and magnetic flux density distribution of the $45 \mathrm{~kW}$-class MG-PMSM with a concentrated winding. The detailed values of the design variables are shown in Figure 11. Figure 12 shows the Back-EMF, rated torque, and efficiency characteristics of the final design model derived by the analytical method. Finally, Table 6 shows the derivation results of the detailed design model of $45 \mathrm{~kW}$-class MG-PMSM with a concentrated winding. In conclusion, through the detailed design of the final model, the rated current of the $45 \mathrm{~kW}$-class MG-PMSM with concentrated winding could be reduced by $23 \%$ and the volume by $9.5 \%$, and the efficiency could be increased by $0.2 \%$.

Table 6. Derivation results of the Detailed Design Model of 45kW-class MG-PMSM with Concentrated winding.

\begin{tabular}{cc}
\hline Contents & Value \\
\hline Outer Dia. Of stator/Stack length/Axial length with end turns & $520 / 160 / 190 \mathrm{~mm}$ \\
\hline DC link voltage/I ${ }_{\text {Phase }}$ @ Rated speed & $750 \mathrm{~V}_{\mathrm{dc}} / 199 \mathrm{~A}_{\mathrm{rms}}$ \\
\hline $\mathrm{T}_{\text {ave._rated } / \text { Torque ripple @ Rated speed }}$ & $2083 \mathrm{Nm} / 6.8 \%$ \\
\hline THD of Back-EMF (No-load/Full-load) @ Rated speed & $4.0 / 4.2 \%$ \\
\hline Back-EMF ${ }_{\text {Phase-fund. }}$ M Max. speed & $385 \mathrm{~V}$ \\
\hline Copper loss/Iron loss/Eddy current loss in PM @ Rated speed & $883 / 85 / 524 \mathrm{~W}$ \\
\hline Efficiency @ Rated speed & $96.9 \%$ \\
\hline
\end{tabular}




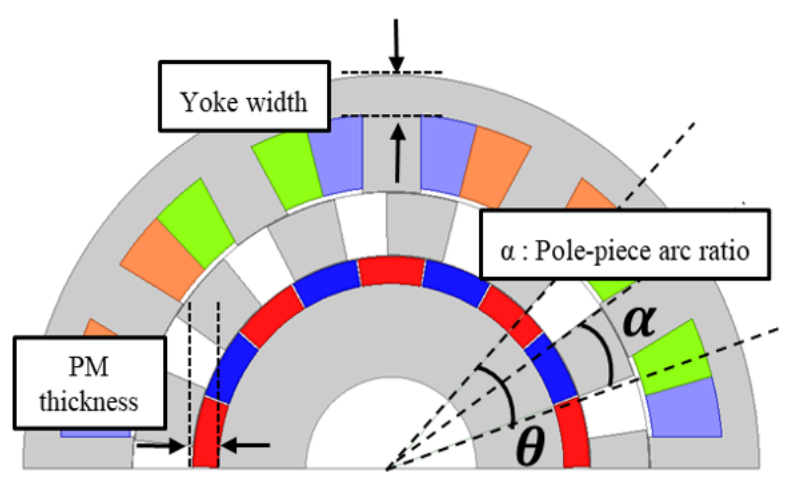

(a)

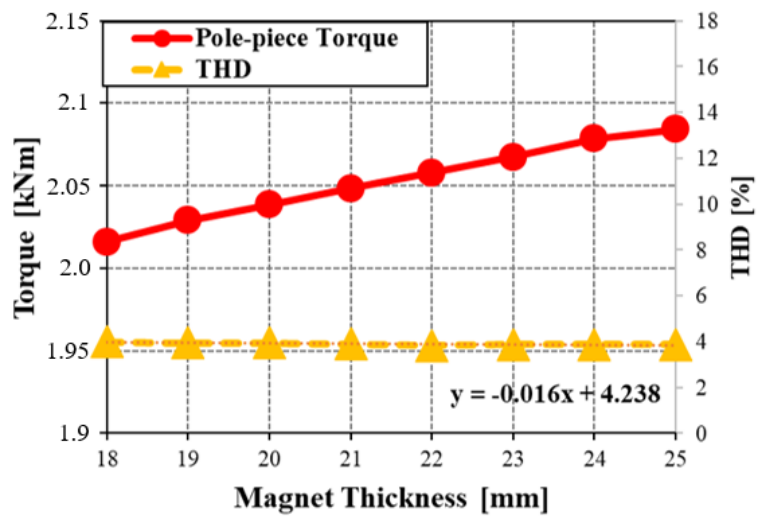

(c)

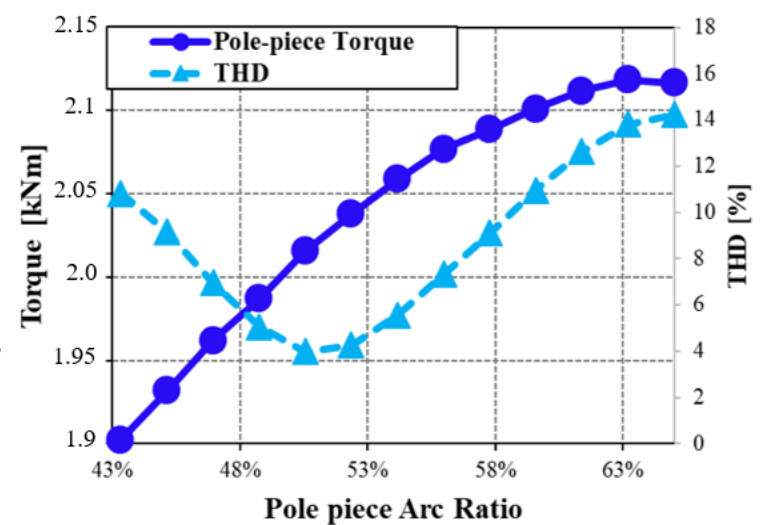

(b)

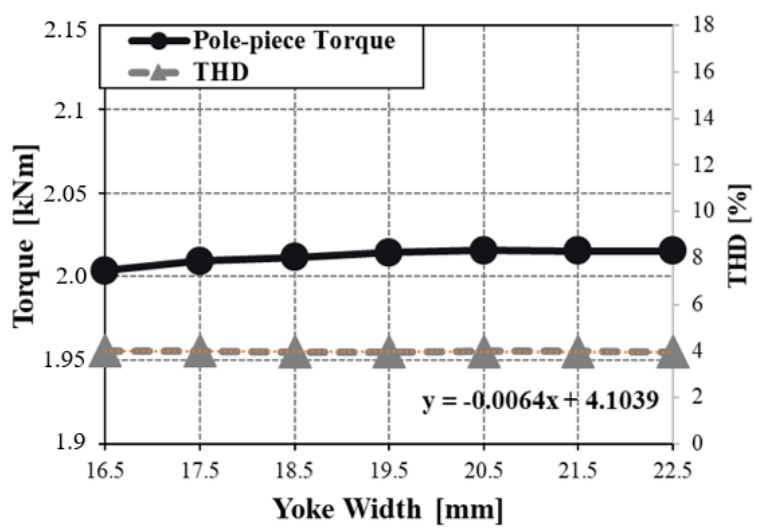

(d)

Figure 10. Detailed design parameters selected to derive the final 45kW MG-PMSM model and the results of sensitivity analysis of parameters: (a) Design parameters for sensitivity analysis; (b) Effects of change in PP arc-ratio; (c) Effects of change in PM thickness; (d) Effects of change in yoke width.

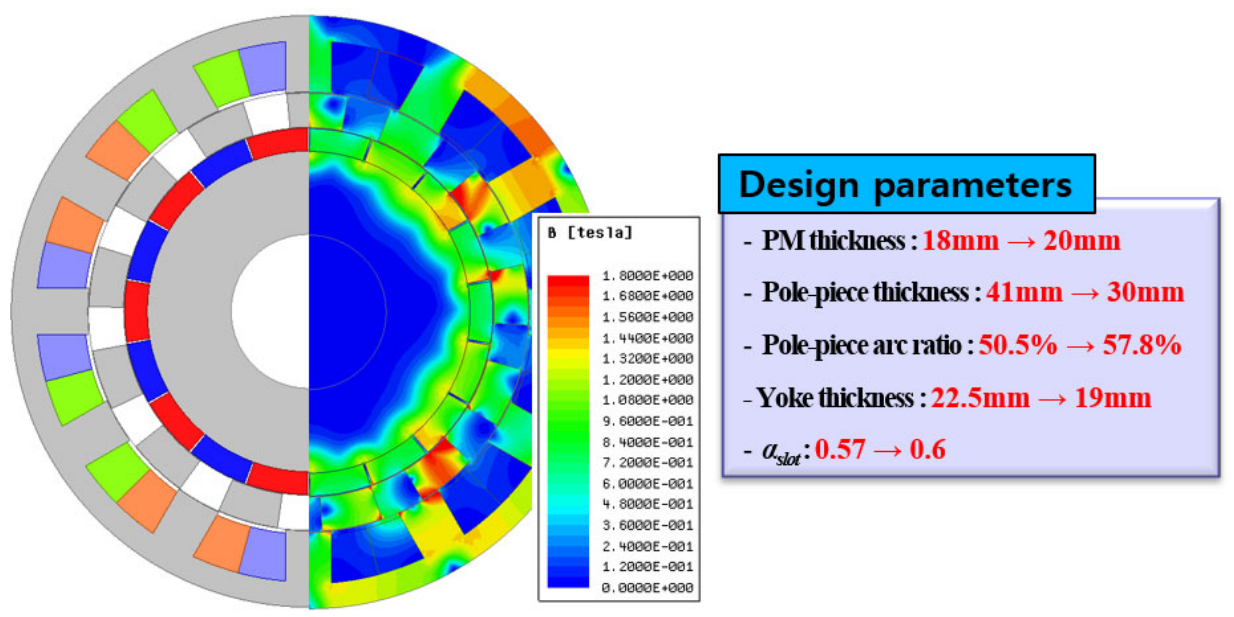

Figure 11. Final design model and magnetic flux density distribution of the 45kW-class MG-PMSM with a concentrated winding. 


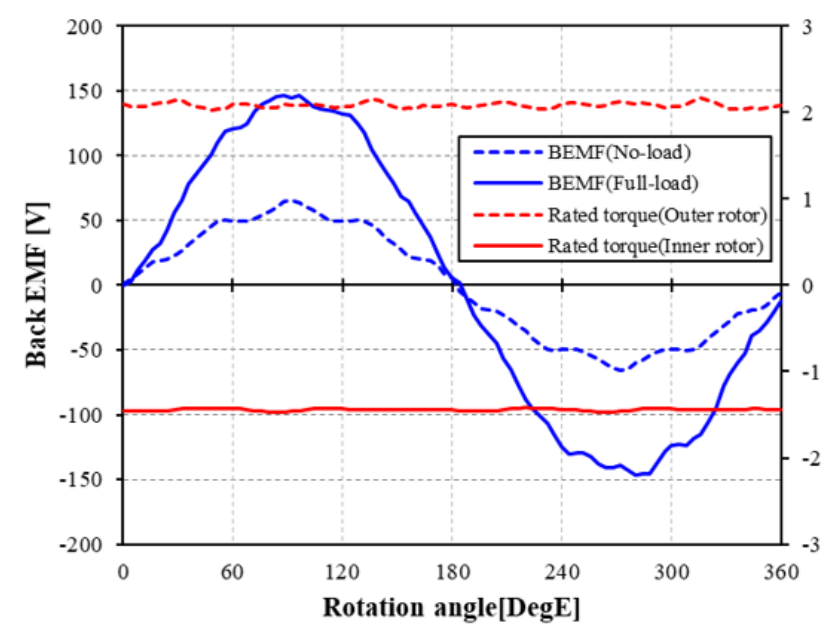

(a)

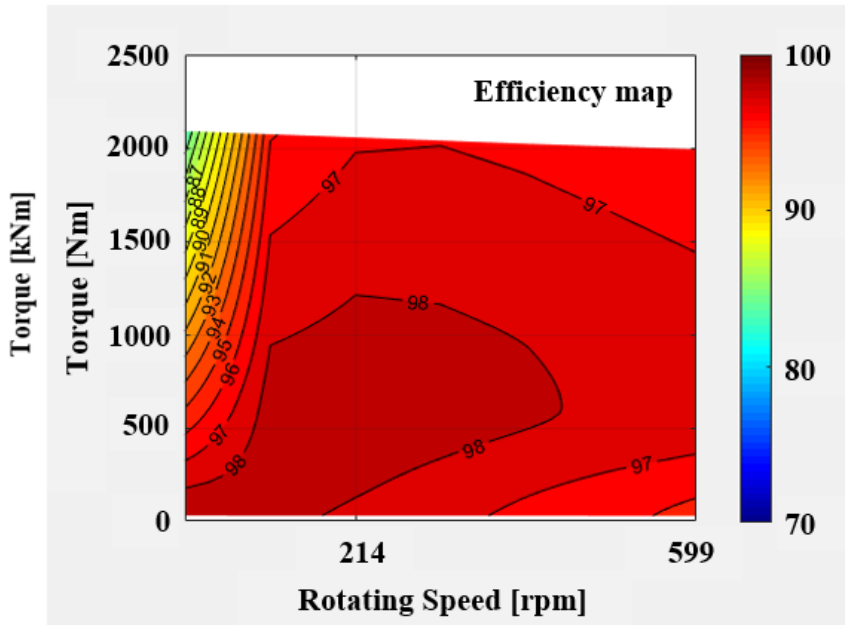

(b)

Figure 12. Performance characteristics of the final design model: (a) Back-EMF and rated torque characteristics; (b) Torque and efficiency map.

\section{Verification of Design Method Using a Small-Scaled MG-PMSM Prototype \\ 4.1. Derivation of the Design Model for 4.5kW-Class Small-Scaled MG-PMSM}

In order to accurately verify the validity of the $45 \mathrm{~kW}$-class MG-PMSM design method presented in this research, the MG-PMSM prototype with the $45 \mathrm{~kW}$-class capacity must be applied. However, the cost and test-bed conditions are not satisfied to evaluate the performance of the MG-PMSM prototype with a $45 \mathrm{~kW}$-class capacity. Therefore, a 1/10 scale-down prototype was produced considering the available budget and test bed conditions in this research.

First, a design model of a 4.5kW-class small-scaled MG-PMSM was derived by applying the design method suggested in this research. The design requirements of the 4.5kW-class small-scaled MG-PMSM are 200.4 Nm and 71.8 Nm, respectively, at rated speed and maximum speed, and the Back-EMF voltage limit is $433 \mathrm{~V}_{\text {peak }}$, and the efficiency is over $92 \%$. Table 7 shows the derivation results of the final design model of the $4.5 \mathrm{~kW}$-class small-scaled MG-PMSM prototype. As shown in Table 7, it can be confirmed that the electromagnetic characteristics of the derived design model satisfy the design requirements. Figure 13 shows the performance characteristics of the final design model. As shown in Figure 13, the Back-EMF of the final designed model does not exceed the voltage limit under the full-load condition, and the torque characteristics also satisfy the design requirements. 
Table 7. Derivation results of the final design model of $4.5 \mathrm{~kW}$-class small-scaled MG-PMSM prototype.

\begin{tabular}{|c|c|c|}
\hline Design Model and Magnetic Flux Density Distribution & Contents & Value \\
\hline & Outer Dia. of stator & $260 \mathrm{~mm}$ \\
\hline & Stack length of stator & $210 \mathrm{~mm}$ \\
\hline & Gear ratio $1 / 2$ & $4.5 / 3.5$ \\
\hline $1.62008++000$ & I Phase @ Rated speed & $16 \mathrm{~A}_{\mathrm{rms}}$ \\
\hline $\begin{array}{l}1.4850 \mathrm{E}+600 \\
1.3500 \mathrm{E}+000\end{array}$ & $\mathrm{~T}_{\text {ave._rated }} @$ Rated/Max. speed & $236.2 / 78.6 \mathrm{Nm}$ \\
\hline $\begin{array}{l}1.2150 \mathrm{E}+000 \\
1.9800 \mathrm{E}+800\end{array}$ & $\mathrm{~T}_{\text {ripple }} @$ Rated /Max. speed & $5.4 / 21.5 \%$ \\
\hline $\begin{array}{l}9.4500 \mathrm{E}-601 \\
8.1000 \mathrm{E}-001\end{array}$ & Phase resistance @ $20^{\circ} \mathrm{C}$ & $0.77 \Omega$ \\
\hline $\begin{array}{l}6.7500 E-801 \\
5.4000 E-601\end{array}$ & Back-EMF $F_{\text {Phase-fund. }} @$ Max. speed & 422.1 V @ Full-load \\
\hline $\begin{array}{l}1.3500 \mathrm{E}-6061 \\
0.000 \mathrm{E}+600\end{array}$ & Efficiency@ Rated speed & $96.1 \%$ \\
\hline
\end{tabular}

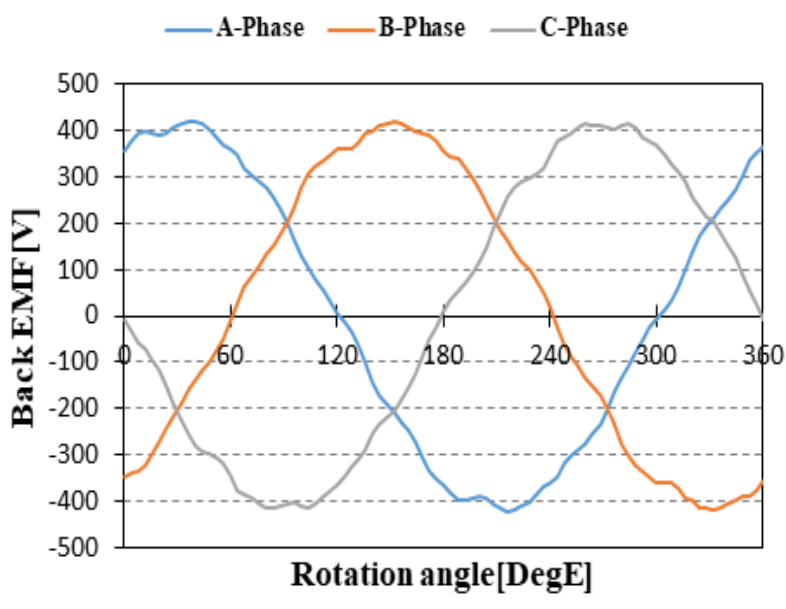

(a)

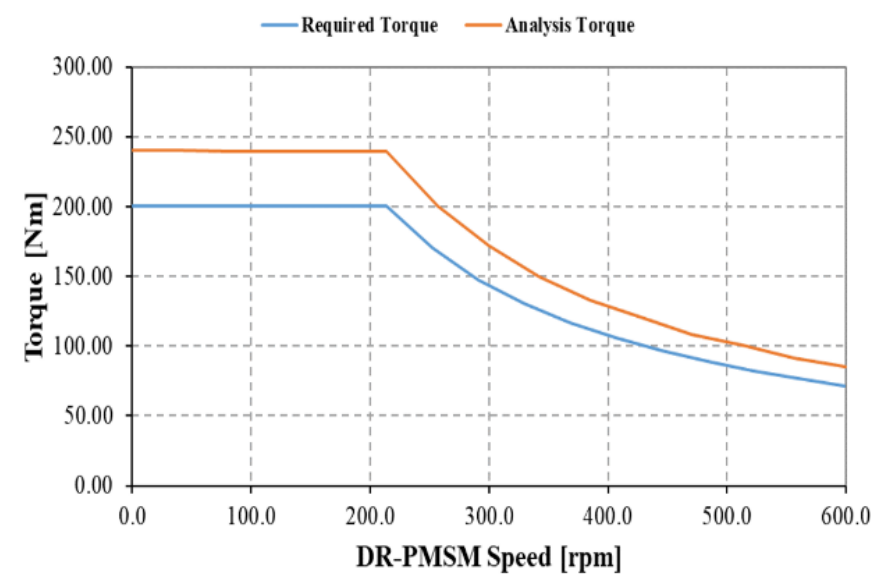

(b)

Figure 13. Electromagnetic characteristics of the final design model: (a) Back-EMF characteristics (599 rpm, full-load); (b) Torque characteristics.

4.2. Verification of Design Method through Performance Test of the 4.5kW-Class Small-Scaled MG-PMSM Prototype

The 4.5kW-class small-scaled MG-PMSM prototype with concentrated winding is manufactured to verify the validity of the MG-PMSM design method in this research. Figure 14 shows the arrangement of the parts for the assembly of a $4.5 \mathrm{~kW}$-class smallscaled MG-PMSM and assembled prototype. As shown in Figure 14, the outer rotor (pole pieces rotor) of the MG-PMSM prototype is composed of pole pieces and epoxy resin. The pole pieces rotor is made of a laminated silicon steel sheet to reduce the eddy current loss, and the slots between the pole pieces are filled with epoxy resin to secure the rigidity of the rotor. Figure 15 shows a setup of dual load performance tester and peripheral devices for measuring the driving characteristics of the $4.5 \mathrm{~kW}$-class MG-PMSM prototype ((a) Schematic block diagram related to measurement setup; (b) Measurement set). As shown in Figure 15a, two servo motors are applied to the dual load performance tester. 

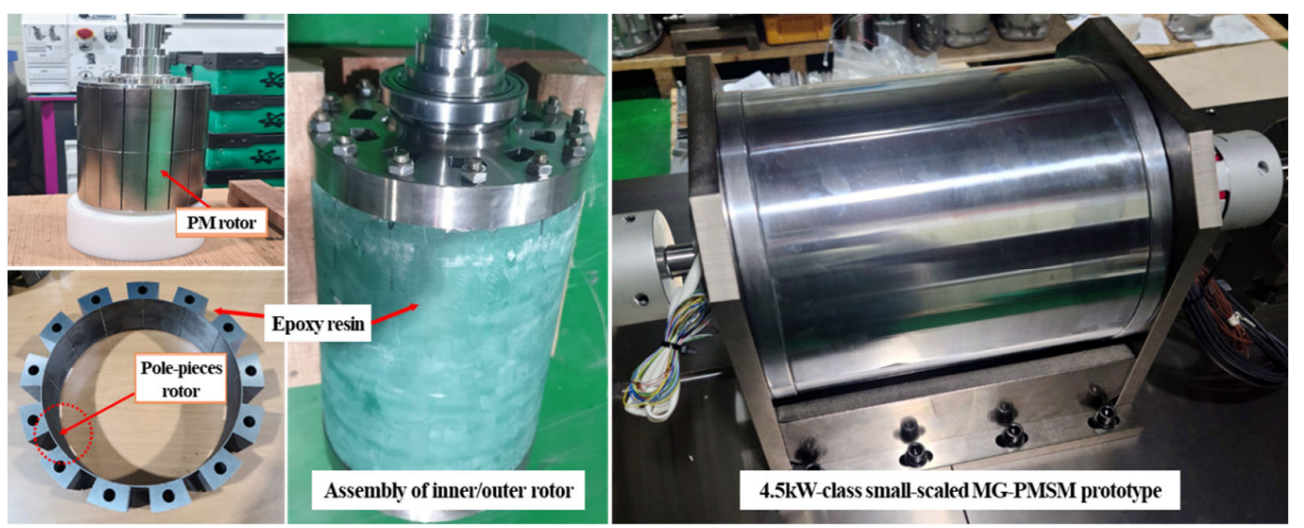

Figure 14. Parts arrangement for assembly of 4.5kW-class MG-PMSM and assembled prototype.

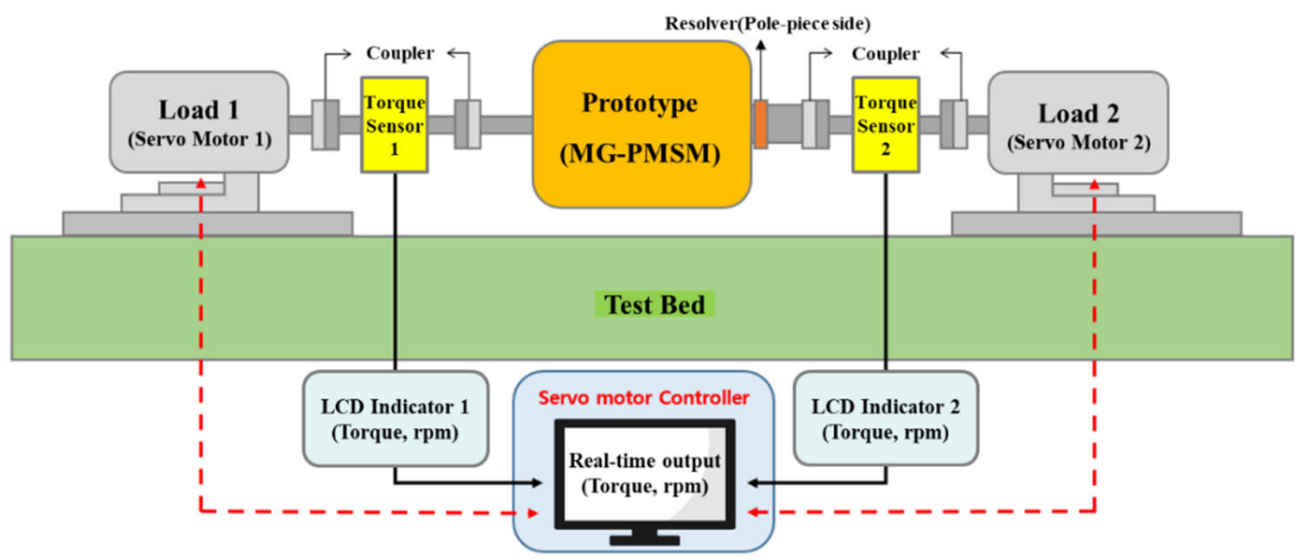

(a)

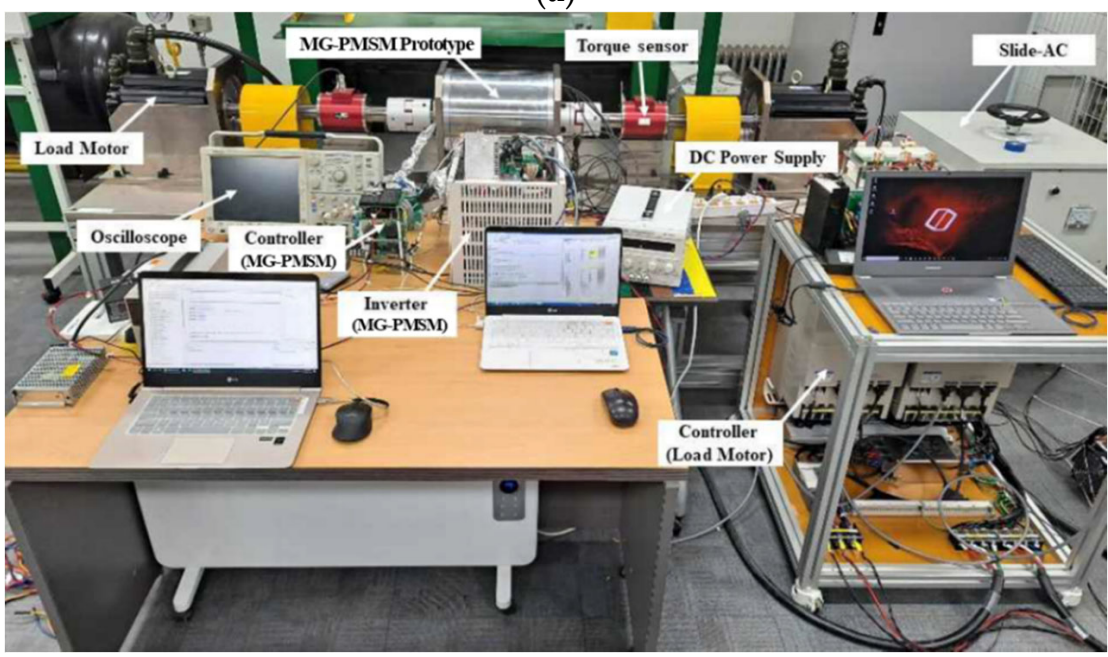

(b)

Figure 15. Setup of dual load performance tester and peripheral devices for measuring the driving characteristics of $4.5 \mathrm{~kW}$-class MG-PMSM prototype. (a) Schematic block diagram related to measurement setup; (b) Measurement set.

In this research, the validation of the design method and parameters were verified through the no-load and load performance test of the 4.5kW-class small-scaled MG-PMSM prototype. Figure 16 shows the measurement and calculation wave comparison of the no-load phase Back-EMF of the 4.5kW-class MG-PMSM prototype. Under this no-load condition, the Back-EMF is measured using the dual servo motor of the performance tester 
while the pole piece rotor and PM rotor rotate at $214 \mathrm{rpm}$ and $155 \mathrm{rpm}$, respectively. Table 8 shows the comparison results between the calculated value and measured value of no-load Back-EMF at the rated speed (pole piece/PM rotor@214/155 rpm). As shown in Table 8, the measured value is $68.6 \mathrm{~V}_{\text {fund.-peak }}$ at the rated speed based on the fundamental wave peak value of phase Back-EMF, the calculated value is $72.3 \mathrm{~V}_{\text {fund.-peak, }}$ and the difference ratio is about $5.1 \%$. The difference between the calculated value of the Back-EMF and the measured value is due to the additionally included harmonic components in the measured waveform. Here, it is found that harmonic components are additionally included in the Back-EMF waveform due to the non-uniformity of the air gap due to the manufacturing tolerance of the MG-PMSM prototype.

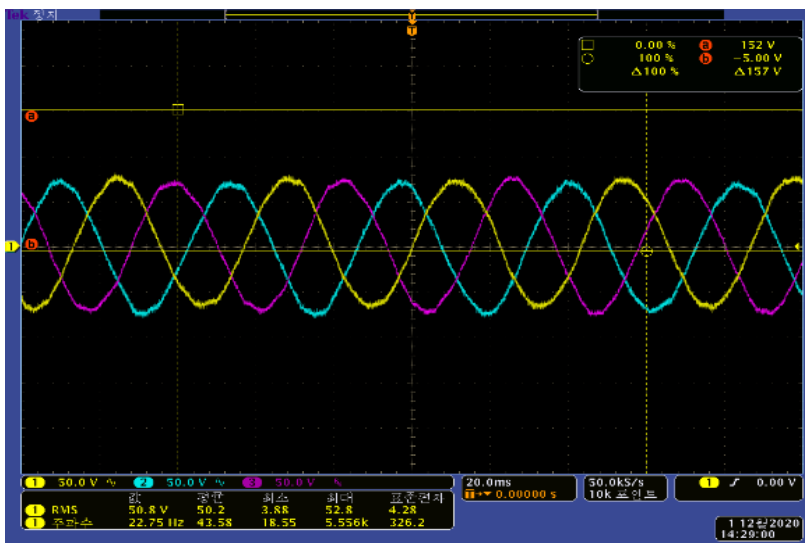

(a)

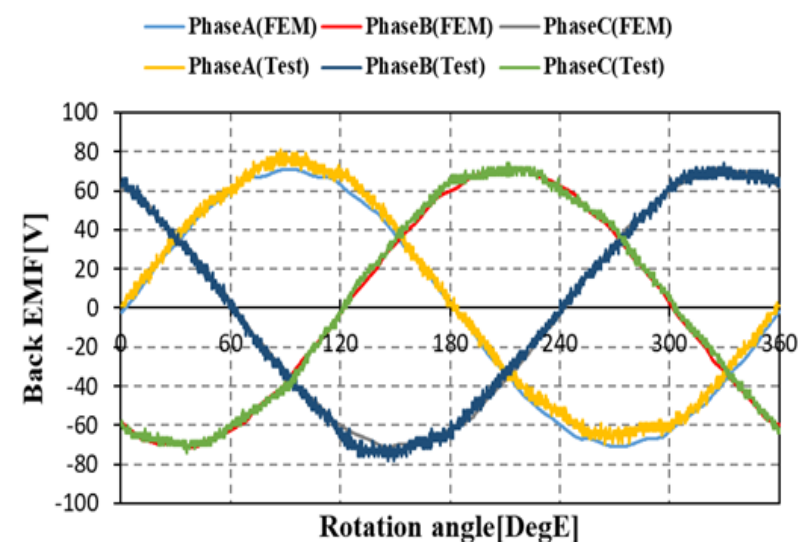

(b)

Figure 16. Measurement and calculation wave comparison of no-load phase Back-EMF of 4.5kW-class MG-PMSM prototype (pole piece/PM rotor@214/155 rpm): (a) Experimental wave; (b) Calculated wave.

Table 8. Comparison results between calculated value and measured value of no-load Back-EMF at rated speed (pole piece/PM rotor@214/155 rpm).

\begin{tabular}{cccc}
\hline Contents & Calculation & Measurement & Difference Rate \\
\hline Back-EMF & $50.0 \mathrm{~V}$ & $50.2 \mathrm{~V}$ & $0.4 \%$ \\
\hline $\begin{array}{c}\text { Back- } \\
\mathrm{EMF}_{\text {Phase-fund.-peak }}\end{array}$ & $72.3 \mathrm{~V}$ & $68.6 \mathrm{~V}$ & $5.1 \%$ \\
\hline Frequency & $23.18 \mathrm{~Hz}$ & $22.75 \mathrm{~Hz}$ & $1.9 \%$ \\
\hline
\end{tabular}

Next, the load performance test is conducted by applying servo motors for load devices to the pole piece rotor and the PM rotor, respectively. The load performance test was performed by measuring the torque generated while changing the input current of the $4.5 \mathrm{~kW}$-class MG-PMSM prototype for each speed through the speed command of the servo motors. Figure 17 shows the measurement result by load performance test of the 4.5kW-class MG-PMSM prototype. Figure 17a,b shows the 3-phase input current waveform and the generated torque waveform in the pole piece rotor under the following driving conditions, respectively (pole piece/PM rotor@30/-21 rpm, $\mathrm{I}_{\text {phase }}=3 \mathrm{~A} / 6.5 \mathrm{~Hz}$ ). In addition, the unbalance of the 3-phase input current occurs more significantly in the load test than in the no-load test. Some torque ripple occurs during the load test due to manufacturing and mechanical errors of the MG-PMSM prototype, but it is confirmed that the pole piece rotor torque converges to about $41.3 \mathrm{Nm}$. Figure 18 shows the comparison of the experimental and calculated values of the torque generated in the pole piece rotor by the load performance test of the $4.5 \mathrm{~kW}$-class MG-PMSM prototype. Figure 18a shows the comparison results when the rotational speeds of the pole piece rotor are 30 and 45 rpm, and Figure 18b shows the torque error rate distribution between experimental and 
calculated values in the low speed-torque region. As shown in Figure 18, when comparing the experimental results and calculated results related to the torque generated in the pole pieces rotor, it can be confirmed that the difference rate is up to $11 \%$. The large difference between the experimental results and the calculated results is caused by the accumulation of measurement errors due to increased torque ripple due to the eccentricity of the rotor due to poor manufacturing of the pole pieces rotor during the manufacturing of the MGPMSM prototype. In particular, it showed a tendency to generate a large torque error as the vibration of the MG-PMSM prototype increased in the region where the input current and rotation speed were large. As shown in Figure 18b, it was confirmed that the error rate within $5 \%$ was kept constant in the stable operation area where vibration did not occur significantly according to the comparison result between the analysis value and the test value of the torque generated by the input current according to the pole piece rotation speed of MG-PMSM prototype.

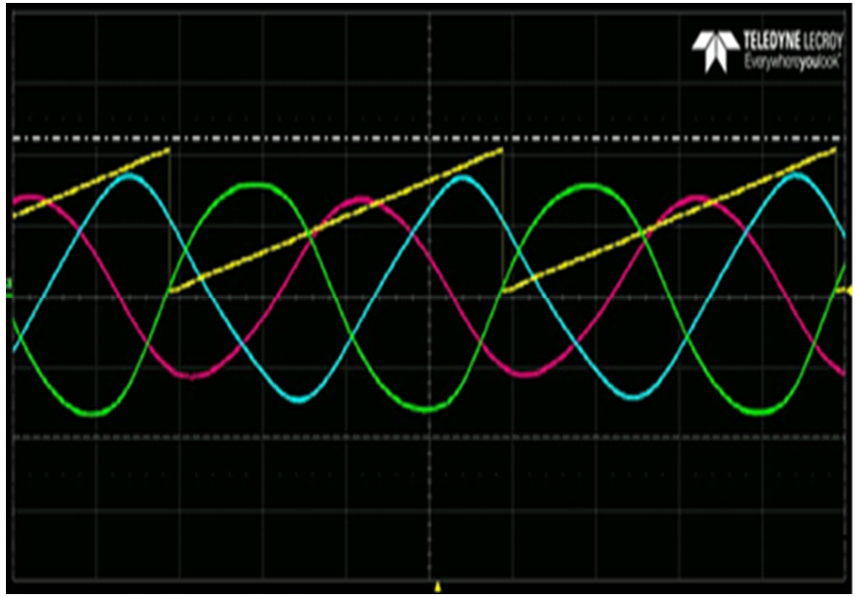

(a)

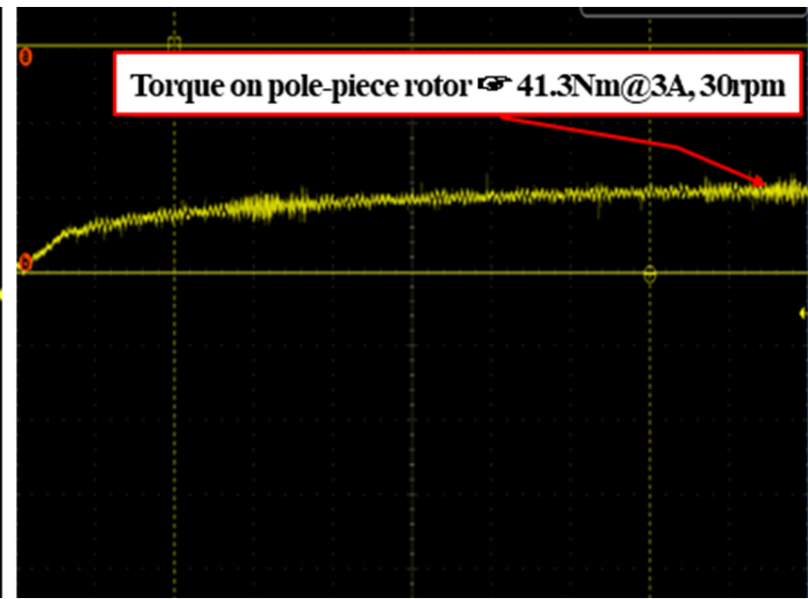

(b)

Figure 17. Measurement result by load performance test of 4.5kW-class MG-PMSM prototype (pole piece/PM rotor@30/21 rpm): (a) Phase of 3-phase current $(6.5 \mathrm{~Hz}, 3 \mathrm{~A})$; (b) Torque on the pole piece rotor.

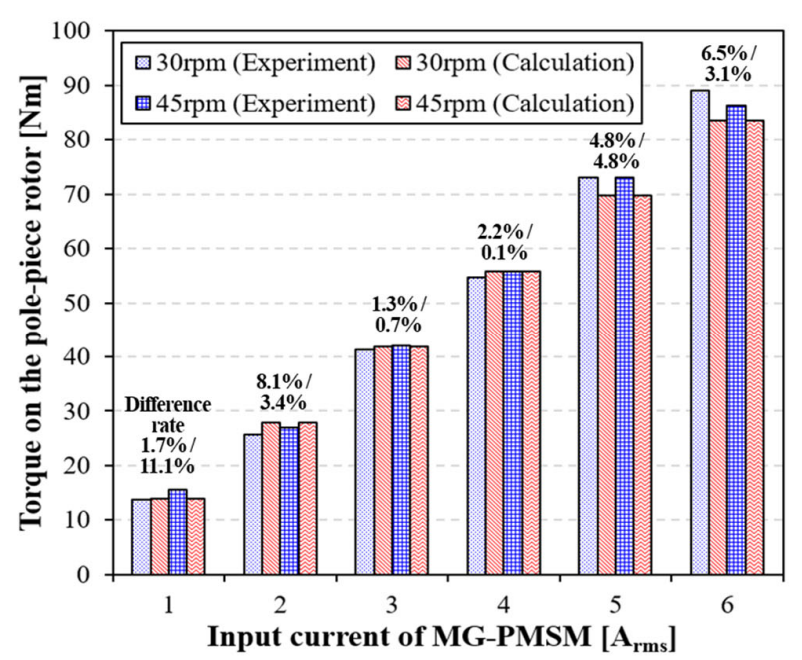

(a)

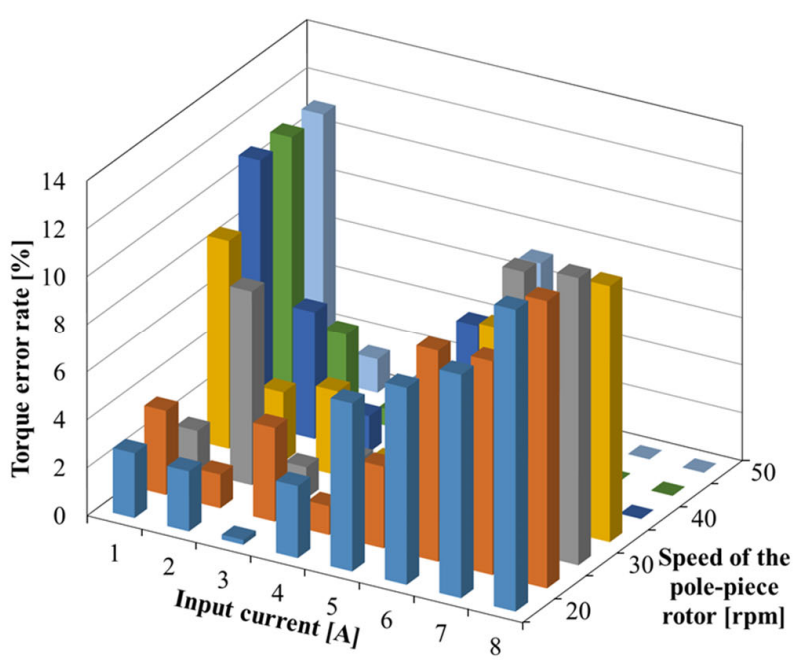

(b)

Figure 18. Comparison of the experimental and calculated values of the torque generated in the pole piece rotor by the load performance test of 4.5kW-class MG-PMSM prototype: (a) Rotational speed of the pole piece rotor: 30 and $45 \mathrm{rpm}$; (b) Torque error rate distribution between experimental and calculated values in the low speed-torque region. 
In this research, there was a problem where the vibration increased when the load increased due to the non-uniformity of the air gap caused by the eccentricity of the pole pieces rotor, and for this reason, it was not possible to proceed to the rated load test. However, the effectiveness of the design method of MG-PMSM presented in this research is partially verified through the light load test results of the $4.5 \mathrm{~kW}$-class small-scaled MGPMSM prototype. In the future, we plan to additionally proceed with the rated load test through the modification of the pole pieces rotor.

\section{Conclusions}

In this research, the design study of the 45kW-class MG-PMSM was conducted for the application of the MG-PMSM to the driving system for a tram. Since the MG-PMSM must be installed in the bogie space where the conventional mechanical reduction gear system is mounted, minimizing the size of the MG-PMSM was the main design goal in this research. First, to derive the detailed model of the 45kW-class MG-PMSM for the tram, the analysis of the characteristics according to the stator winding method (distributed and concentrated windings) was performed. In the case of the MG-PMSM with the distributed winding, there was a problem where the axial length of the MG-PMSM did not satisfy the requirements due to a large end-turn part. After selecting the concentrated winding method that could reduce the end-turn size of the MG-PMSM, two design topologies were applied to determine the number of stator poles, the number of outer rotor pole pieces, and the number of inner rotor poles of the MG-PMSM. The final selected design topology is a method of using the number of pole pairs of the stator to derive the number of pole pieces, and the detailed model design was conducted to verify the design topology. The detailed model was derived by applying the selected design topology that can minimize the size of the MG-PMSM. In conclusion, through the detailed design of the final model, the rated current of the $45 \mathrm{~kW}$-class MG-PMSM with concentrated winding could be reduced by $23 \%$ and the volume by $9.5 \%$, and the efficiency could be increased by $0.2 \%$.

In addition, the $4.5 \mathrm{~kW}$-class small-scaled MG-PMSM prototype with concentrated winding was fabricated to verify the validity of the analytical model, and performance verification was performed. The validation of the design method and parameters were verified through the no-load and load performance test of the MG-PMSM prototype. Although the rated load test could not be conducted due to instability due to the eccentricity of the pole pieces rotor, the dynamic performance of the MG-PMSM prototype was derived through the light load test and compared with the FEM simulation results. In conclusion, the effectiveness of the design method of MG-PMSM presented in this research is partially verified through the light load test results of the $4.5 \mathrm{~kW}$-class small-scaled MG-PMSM prototype. In the future, we plan to additionally proceed with the rated load test through the modification of the pole pieces rotor.

Author Contributions: Conceptualization, C.-B.P.; methodology, C.-B.P. and H.-W.L.; software, J.H.L. and G.J.; validation, J.-B.L. and J.-S.L.; formal analysis, J.-H.L. and G.J.; investigation, C.-B.P.; writing—original draft preparation, J.-H.L.; writing—review and editing, C.-B.P.; visualization, J.H.L.; supervision, C.-B.P.; project administration, C.-B.P.; funding acquisition, C.-B.P. All authors have read and agreed to the published version of the manuscript.

Funding: This work is supported by the Korea Agency for Infrastructure Technology Advancement (KAIA) grant funded by the Ministry of Land, Infrastructure and Transport (Grant 21RSCD-C163329-01).

Institutional Review Board Statement: Not applicable.

Informed Consent Statement: Not applicable.

Data Availability Statement: Not applicable.

Conflicts of Interest: The authors declare no conflict of interest. The funders had no role in the design of the study; in the collection, analyses, or interpretation of data; in the writing of the manuscript, or in the decision to publish the results. 


\section{References}

1. Zhang, X.; Huang, Y.H. Influence of anti-kink system on curve negotiation performance of low-floor tram. Urban Rail Transit Res. 2018, 21, 111-116.

2. Hondius, H. The development of low-flow trams. J. Adv. Transp. 1993, 27, 79-102. [CrossRef]

3. Atallah, K.; Calverley, S.D.; Howe, D. Design, analysis and realization of a high-performance magnetic gear. IEE Proc. Electr. Power Appl. 2004, 151, 135-143. [CrossRef]

4. Park, C.B.; Jeong, G. Performance verification of DR-PMSM for traction system according to permanent magnet shape. AIP Adv. 2020, 10, 025105. [CrossRef]

5. McGilton, B.; Crozier, R.; McDonald, A.; Mueller, M. Review of magnetic gear technologies and their applications in marine energy. IET Renew. Power Gener. 2018, 12, 174-181. [CrossRef]

6. Sun, L.; Cheng, M.; Jia, H. Analysis of a novel magnetic-geared dual-rotor motor with complementary structure. IEEE Trans. Ind. Electron. 2015, 62, 6737-6747. [CrossRef]

7. Sun, L.; Cheng, M.; Zhang, J.; Song, L. Analysis and control of complementary magnetic-geared dual-rotor motor. IEEE Trans. Ind. Electron. 2016, 63, 6715-6725. [CrossRef]

8. Sun, L.; Cheng, M. Key Issues in Design and Manufacture of Magnetic-Geared Dual-Rotor Motor for Hybrid Vehicles. IEEE Trans. Energy Convers. 2017, 32, 1492-1501. [CrossRef]

9. Sun, L.; Cheng, M.; Wen, H.; Song, L. Motion Control and Performance Evaluation of a Magnetic-Geared Dual-Rotor Motor in Hybrid Powertrain. IEEE Trans. Ind. Electron. 2016, 64, 1863-1872. [CrossRef]

10. Zhao, H.; Liu, C.; Song, Z.; Liu, S. A Consequent-Pole PM Magnetic-Geared Double-Rotor Machine with Flux-Weakening Ability for Hybrid Electric Vehicle Application. IEEE Trans. Magn. 2019, 55, 7. [CrossRef]

11. Shin, K.H.; Cho, H.W.; Kim, K.H.; Hong, K.; Choi, J.Y. Analytical Investigation of the On-Load Electromagnetic Performance of Magnetic-Geared Permanent-Magnet Machines. IEEE Trans. Magn. 2018, 54, 11. [CrossRef]

12. Shin, H.; Chang, J. Comparison of radial force at modulating pieces in coaxial magnetic gear and magnetic geared machine. IEEE Trans. Magn. 2018, 54, 3. [CrossRef]

13. Chau, K.T.; Zhang, D.; Jiang, J.Z.; Liu, C.; Zhang, Y. Design of a Dual-rotor outer-rotor permanent-magnet brushless motor for electric vehicles. IEEE Trans. Magn. 2007, 43, 2504-2506. [CrossRef]

14. Niguchi, N.; Hirata, K. Torque-speed characteristics analysis of a magnetic-geared motor using finite element method coupled with vector control. IEEE Trans. Magn. 2013, 49, 2401-2404. [CrossRef]

15. Niguchi, N.; Hirata, K. Cogging torque characteristics of magnetic geared motor. In Proceedings of the XV International Symposium on Electromagnetic Fields in Mechatronics, Electrical and Electronic Engineering (ISEF2011), Funchal, Portugal, 1-3 September 2011.

16. Morimoto, E.; Niguchi, N.; Hirata, K. Magnetic-geared motor with a continuously variable transmission gear ratio and its control method. Electron. Commun. JPN 2018, 101, 16-26. [CrossRef]

17. Park, C.B.; Jung, D.H.; Jeong, G. Wireless tram propulsion system specification analysis and magnetic gear design strategy. J. Korean Soc. Railw. 2020, 23, 784-793. [CrossRef]

18. Korea Railroad Research Institute. Development of system technology for wireless low-floor tram. In Land, Infrastructure and Transportation RED Report; KRRI: Uiwan-si, Korea, 2013.

19. Park, C.B.; Jeong, G. Design and Analysis of Dual-rotor Permanent Magnet Synchronous Motor for Driving Electric Vehicles. In Proceedings of the ICEMS 2017 Conferences, Sydney, Australia, 11-14 August 2017.

20. Lee, J.J.; Kim, W.H.; Yu, J.S.; Yun, S.Y.; Kim, S.M.; Lee, J.J.; Lee, J. Comparison between concentrated and distributed winding in IPMSM for traction application. In Proceedings of the 2010 International Conference on Electrical Machines and Systems, Incheon, Korea, 10-13 October 2010.

21. Munoz, A.R.; Liang, F.; Degner, M.W. Evaluation of Interior PM and Surface PM Synchronous Machines with Distributed and Concentrated Winding, Industrial Eletronics, 2008. In Proceedings of the IECON 2008-34th Annual Conference of IEEE, Orlando, FL, USA, 10-13 November 2008; pp. 1189-1193. 